\title{
IMMII Access, Interest, and Attitudes Toward Electronic Communication for Health Care Among Patients in the Medical Safety Net
}

\author{
Adam Schickedanz, $M D^{7}$, David Huang, $M D^{2}$, Andrea Lopez, BS ${ }^{3}$, Edna Cheung, $B A^{4}$, \\ C. R. Lyles, $P h D^{3}$, Tom Bodenheimer, $M D, M P H^{5}$, and Urmimala Sarkar, MD, $M P H^{3}$
}

'Department of Pediatrics, University of California San Francisco, San Francisco, CA, USA; ${ }^{2}$ Department of Internal Medicine, University of California San Francisco, San Francisco, USA; ${ }^{3}$ Center for Vulnerable Populations at San Francisco General Hospital, Department of Internal Medicine, University of California San Francisco, San Francisco, USA; ${ }^{4}$ University of California at Berkeley, Berkeley, USA; ${ }^{5}$ Department of Family and Community Medicine, University of California San Francisco, San Francisco, USA.

BACKGROUND: Electronic and internet-based tools for patient-provider communication are becoming the standard of care, but disparities exist in their adoption among patients. The reasons for these disparities are unclear, and few studies have looked at the potential communication technologies have to benefit vulnerable patient populations.

OBJECTIVE: To characterize access to, interest in, and attitudes toward internet-based communication in an ethnically, economically, and linguistically diverse group of patients from a large urban safety net clinic network.

DESIGN: Observational, cross-sectional study

PARTICIPANTS: Adult patients ( $\geq 18$ years) in six resource-limited community clinics in the San Francisco Department of Public Health (SFDPH)

MAIN MEASURES: Current email use, interest in communicating electronically with health care professionals, barriers to and facilitators of electronic healthrelated communication, and demographic data-all self-reported via survey.

KEY RESULTS: Sixty percent of patients used email, $71 \%$ were interested in using electronic communication with health care providers, and $19 \%$ reported currently using email informally with these providers for health care. Those already using any email were more likely to express interest in using it for health matters. Most patients agreed electronic communication would improve clinic efficiency and overall communication with clinicians.

CONCLUSIONS: A significant majority of safety net patients currently use email, text messaging, and the internet, and they expressed an interest in using these tools for electronic communication with their medical providers. This interest is currently unmet within safety net clinics that do not offer a patient portal or secure messaging. Tools such as email encounters and elec-

Electronic supplementary material The online version of this article (doi:10.1007/s11606-012-2329-5) contains supplementary material, which is available to authorized users.

Received August 14, 2012

Revised November 20, 2012

Accepted December 19, 2012

Published online February 20, 2013 tronic patient portals should be implemented and supported to a greater extent in resource-poor settings, but this will require tailoring these tools to patients' language, literacy level, and experience with communication technology.

KEY WORDS: health information technology; disparities; clinical communication; electronic patient portal.

$\mathrm{J}$ Gen Intern Med 28(7):914-20

DOI: $10.1007 / \mathrm{s} 11606-012-2329-5$

(C) Society of General Internal Medicine 2013

\section{INTRODUCTION}

The Internet's role in health care is growing rapidly. Over three quarters of the U.S. population is connected to the internet, and $59 \%$ of Americans use the internet to access health care resources, obtain medical information, and communicate with others, including their health care providers, to support their health. ${ }^{1}$ Internet-based communication between patients and clinicians is a promising application of health information technology. Electronic patient portals and secure messaging for health-related communication are widely expected to improve health care value through streamlined communication, increased provider efficiency, facilitation of shared decision-making, patient self-management, and greater patient satisfaction. ${ }^{1-6}$ Recent studies have shown that communication between patients and their health care teams via email or a patient portal with secure web messaging can increase patient satisfaction, enhance provider productivity, and improve health care quality. ${ }^{5-8}$

Health and Human Services' inclusion of patient portals as part of 'meaningful use' standards for electronic health records $^{9}$ and the federally legislated financial incentives in the Health Information Technology for Economic and Clinical Health (HITECH) $\mathrm{Act}^{10}$ are making access to these web-based tools for patient-provider communication the standard of care. Despite this, implementation of technologies for health-related electronic communication has lagged, particularly in community health centers. Disparities in adoption of internet-based health communication 
have been shown for patients with lower income, those with less education, racial and ethnic minorities, the uninsured, and those with low literacy or for whom English is not their primary language. ${ }^{11-19}$ These same patient populations already face well-described disparities in health and health care. The digital divide threatens to further harm the health of these vulnerable populations by excluding them from the benefits of internetbased communication with their health care provider. ${ }^{20-22}$ Understanding and advancing the use of health information technology among vulnerable populations has therefore been identified as a national research and policy priority. ${ }^{12,13}$

Moreover, there is evidence of a 'digital divide' in the U.S., particularly an inequity in internet access for those with fewer economic and social resources. ${ }^{9,10}$ Safety net clinics and health systems care for a disproportionate number of patients and communities likely to be disadvantaged by the digital divide. These same clinics often have a significant need for improved communication with their patients. ${ }^{16,17}$ However, a purported lack of access to the internet among low-income populations has led many to question whether the spread of patient portals and internet-based health communication will have benefits for these groups.

While data on electronic health care encounters and patient portal use in large integrated health systems ${ }^{18}$ have shown benefits to patients in these settings, few studies have looked at the potential of these communication technologies to benefit vulnerable populations. To date, access to, interest in, and attitudes toward internet-based tools for patient-provider communication have not been explored in depth in these populations, particularly in low-income, publicly insured or uninsured groups. Therefore, we aimed to characterize access to and interest in internet-based communication in a broadbased and ethnically, economically, and linguistically diverse group of patients from a large urban safety net clinic network.

\section{METHODS}

\section{Participants}

We surveyed adult patients ( $\geq 18$ years) about their access to and interest in health-related electronic communication in six resource-limited community clinic settings within the San Francisco Department of Public Health (SFDPH). These clinic sites are Federally Qualified Health Centers (FQHCs). Minors, those unable to provide consent or with diminished capacity to consent, and those who did not speak English, Spanish, Cantonese or Mandarin were excluded from the study.

\section{Setting}

Clinics where patients were recruited were part of the San Francisco Community Health Network. The Community Health Network (CHNSF) is the County of San Francisco
Department of Public Health's integrated health care delivery system. The CHNSF includes primary care health centers affiliated with an acute care facility, San Francisco General Hospital (SFGH), that also houses multi-specialty clinics. All of the sites have been designated as FQHCs. The clinicians working in the CHNSF primary care sites provide approximately 275,000 visits to more than 60,000 primary care patients. Both health systems have electronic clinical and administrative data systems to support clinical and administrative functions, but without features to support secure messaging through a patient portal. Two of the six clinics are academically affiliated.

\section{Survey Administration}

Patients were approached in SFDPH clinic waiting rooms by study staff. Study investigators introduced themselves, explained that they were conducting a survey to study use of electronic or web-based communication by patients in the clinic, and then asked each patient if he/she was interested in participating in the 10-minute survey. If the patient was agreeable, he/she provided informed consent and the survey was administered. Study investigators asked participants whether they wanted help understanding the survey. If they asked for help, the surveys were intervieweradministered, though this occurred less than $10 \%$ of the time. Most surveys were self-administered. Some patients were called into the clinical visit before completing the survey. The University of California San Francisco Institutional Review Board approved the study.

\section{Measure Development}

Surveys were designed to gather descriptive statistics to characterize patient and provider use of and interest in email, as well as barriers to its use. Surveys were developed by an iterative consensus process with input from primary care providers, experts in communication with populations having low English proficiency, and external experts in patient-facing health information technology. Surveys were revised with feedback from patients and study staff. Surveys were translated into Spanish and Chinese. To ensure accuracy of translation, the surveys were translated back into English by native Spanish and Cantonese speakers. A full copy of the survey is included as an appendix (available online).

Electronic Communication Use and Interest. We examined two electronic communication outcomes: 1) current email use in everyday life and 2) interest in using email to communication specifically with healthcare providers. To assess current use of electronic communication we asked patients, "How often do you use email (either your own account or someone else's)?" The term "email" was used 
throughout the survey as a readily understandable alternative to more technical terms like "patient portal" or "secure electronic messaging". We also captured frequency and location of email use. To assess interest in electronic health-related communication, participants were asked, "Would you like to use email to communicate with your doctor or nurse?" As secondary outcomes, we assessed current use of text messaging and interest in using texts for health care purposes.

Demographic Measures. Demographic characteristics were measured, including gender, age, income, education level, race/ethnicity, self-rated English proficiency, and native language. Although patients did need to speak English, Spanish, Mandarin or Cantonese to participate, we noted their native language in addition to the language in which the survey was administered.

Attitude Measures. A series of questions asked patients their degree of agreement with statements about the impact of email for health care on communication with providers, privacy, work for clinic staff, patient wait times, and efficiency of care (measured as categorical variables with five possible values on a Likert Scale).

\section{Statistical Analysis}

Chi-square tests were used to descriptively assess interest in and use of electronic communication. We examined both current email use and interest in electronic communication with providers by patient demographic characteristics. We also compared interest in electronic communication with providers among those currently using versus not using any email. All analyses were carried out using Microsoft Access and STATA 10 (StataCorp, College Station, TX).

\section{RESULTS}

Of the 594 patients approached for the study, 416 (70\%) agreed to participate. None were excluded subsequent to enrollment, and each participant completed some or all of the survey - 408 of whom responded to at least one outcome of interest. There were also varying amounts of missing data across survey items, ranging from $4 \%$ missing responses for gender to $13 \%$ missingness for self-reported income.

Participants were ethnically and racially diverse, low income, spoke twenty-four different primary languages, and were generally representative of the overall clinic network patient population. Among the participants, 227 (58\%) were female, $306(79 \%)$ were under 60 years old, 245 (69\%) had income less than $\$ 20,000$ per year, $308(81 \%)$ did not identify as white, 211 (55\%) were primarily English speaking, and 98 (25\%) reported poor or no English proficiency at all (Table 1). Fifty-four percent reported they obtained general health information from the internet.

Overall, $60 \%$ used email and $71 \%$ were interested in using email to communicate with health care providers. As expected, those already using email were more likely to express interest in using it for health care communication (Fig. 1). Despite this level of interest, only $19 \%$ of those with email accounts reported having used email informally to communicate with health care providers.

Table 1 displays demographic characteristics by current email use. Factors associated with greater use of email included younger age, income over $\$ 20,000$ per year, being housed $(\mathrm{p}<0.001)$, some college education, white race, speaking primarily Spanish or English, and higher English

Table 1. Patient Characteristics $N=416$

\begin{tabular}{|c|c|c|c|}
\hline \multirow[t]{2}{*}{ Characteristic } & $\begin{array}{l}\text { Number of } \\
\text { participants } \\
\text { with no email } \\
\text { use or access } \\
\text { (percentage) }\end{array}$ & $\begin{array}{l}\text { Number of } \\
\text { participants } \\
\text { with current } \\
\text { email use } \\
\text { (percentage) }\end{array}$ & \multirow[t]{2}{*}{ P-value } \\
\hline & $N=163(40)$ & $N=244(60)$ & \\
\hline \multicolumn{4}{|l|}{ Gender $(N=391)$} \\
\hline Female & $86(56)$ & $141(59)$ & 0.59 \\
\hline Male & $67(44)$ & $96(40)$ & \\
\hline \multirow{2}{*}{\multicolumn{4}{|c|}{ Age $(N=388)$}} \\
\hline & & & \\
\hline$<40$ & $16(11)$ & 109 (46) & $<0.01$ \\
\hline $41-60$ & $69(46)$ & $106(45)$ & \\
\hline$>60$ & $66(44)$ & $22(9)$ & \\
\hline \multicolumn{4}{|l|}{ Income $(N=355)$} \\
\hline$<\$ 20,000$ & $101(77)$ & $140(63)$ & 0.01 \\
\hline$>\$ 20,000$ & $31(23)$ & $83(37)$ & \\
\hline \multicolumn{4}{|l|}{ Housing $(N=378)$} \\
\hline Own & $13(9)$ & $16(7)$ & $<0.01$ \\
\hline Rent & $107(75)$ & $209(89)$ & \\
\hline \multirow{2}{*}{\multicolumn{4}{|c|}{ Education $(N=356)$}} \\
\hline & & & \\
\hline $\begin{array}{l}\text { Did not graduate } \\
\text { high school }\end{array}$ & $46(33)$ & $20(9)$ & $<0.01$ \\
\hline HS/GED & $56(410)$ & $51(23)$ & \\
\hline $\begin{array}{l}\text { Some college or } \\
\text { completed college }\end{array}$ & $31(22)$ & $112(51)$ & \\
\hline Graduate school & $5(4)$ & $35(16)$ & \\
\hline \multicolumn{4}{|l|}{ Race $(N=382)$} \\
\hline $\begin{array}{l}\text { Prefer not to } \\
\text { answer }\end{array}$ & $5(3)$ & $15(6)$ & $<0.01$ \\
\hline $\begin{array}{l}\text { White-Non } \\
\text { Hispanic }\end{array}$ & $9(6)$ & $65(28)$ & \\
\hline Black & $37(25)$ & $53(23)$ & \\
\hline Asian/Pacific Islander & $55(37)$ & 45 (19) & \\
\hline Hispanic & $31(21)$ & $47(20)$ & \\
\hline Other & $10(7)$ & $10(4)$ & \\
\hline \multicolumn{4}{|l|}{ Language $(N=384)$} \\
\hline English & $68(46)$ & $143(61)$ & $<0.01$ \\
\hline Spanish & $25(17)$ & 35 (15) & \\
\hline Cantonese & $40(27)$ & $21(9)$ & \\
\hline Other & $16(11)$ & $36(15)$ & \\
\hline \multicolumn{4}{|l|}{$\begin{array}{l}\text { English Proficiency } \\
(N=385)\end{array}$} \\
\hline Very good & $71(47)$ & $165(70)$ & $<0.01$ \\
\hline Good & $20(13)$ & $31(13)$ & \\
\hline Not good & $28(19)$ & $33(14)$ & \\
\hline Not at all & $31(21)$ & $6(3)$ & \\
\hline
\end{tabular}

*Some missing values, so the actual denominator is listed for each characteristic 


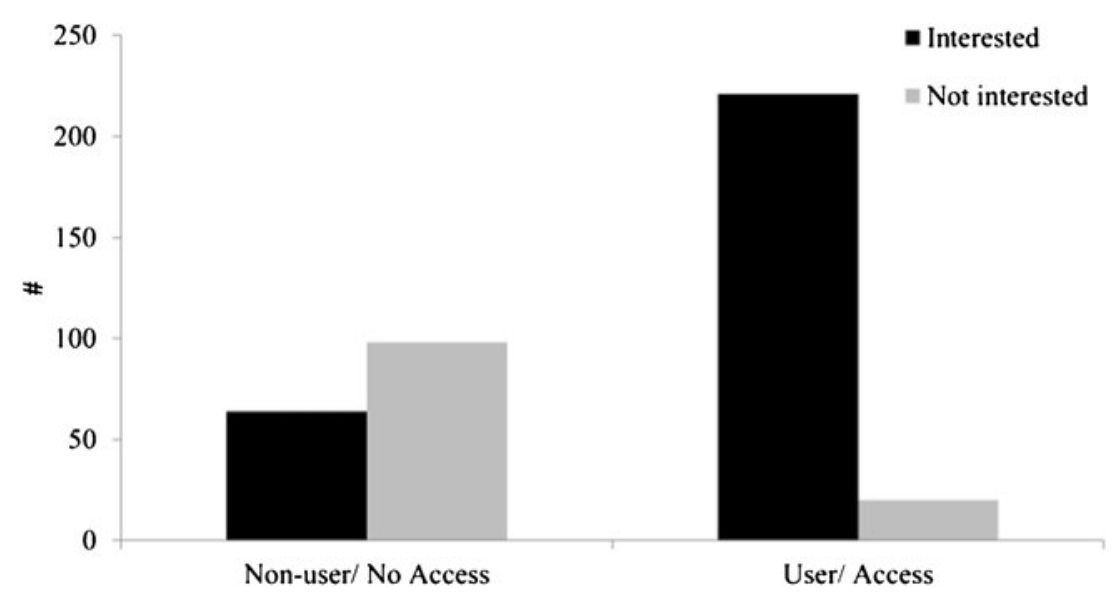

Figure 1. Participants interested in using email to communicate with health provider by whether or not they had access to email.

proficiency. Participants who spoke Cantonese language and reported Asian descent were less likely to use email and less likely to be interested in electronic health-related communication. Participants who were white, AfricanAmerican, or had a higher level of education (college or above) tended to use email more frequently than other groups, with over $50 \%$ of participants in each of these groups checking email on a daily basis or more. Among respondents who use email, most do so from home (59\%), followed by the library ( $28 \%$ ), a friend or relative's house $(8 \%)$, school $(3 \%)$, or somewhere else $(5 \%)$. Less than one quarter of those who used email received help from friends or family to get online.

Next, we examined patient demographics by interest in electronic communication with providers. The strongest predictor of interest in email use for health-related communication among our study participants was any current email use, with only $8 \%$ with email access not being interested in using email to contact their medical providers (Fig. 1). A high level of interest in email for health-related communication among Spanish-speaking participants in our survey (Fig. 2) may be explained in part by a trend toward younger patient age among Spanish-speaking survey participants, but this trend persisted even after adjusting for age ( $p=$ 0.052) (Table 2).

Among those participants who did not use email, $40 \%$ stated that they would be interested in using email to communicate with their providers if such an email system were available to them. Limiting the comparison to those not currently using email, there was no difference in interest in electronic communication with providers by gender, income, housing status, education, or ethnicity. Non-email users not interested in electronic communication with health care providers were older on average (52.5 years old versus 47.8 years old), had lower English proficiency (46\% versus $69 \%$ rated "very good" or above, $p=0.03$ ), and were marginally more likely speak
Cantonese or be of Asian descent ( $29 \%$ vs. $16 \%, p=0.07$; $35 \%$. vs $16 \%, p=0.07$, respectively).

Electronic communication technologies other than email were commonly used among study participants. Fifty-five percent sent or received text messages. Among the subset of that group using text messages, most $(87 \%)$ were interested in texting for health-related communication such as clinic appointment reminders. When asked how long it should take a clinician to reply to a patient email, $41 \%$ said less than 24 hours, and $84 \%$ said it should take 72 hours or less.

Most participants agreed that email encounters would help to improve clinic efficiency through faster contact with providers, to avoid unnecessary visits, and to improve overall communication with clinicians. There were concerns that email would not be useful, because face-to-face visits may be needed to discuss health issues and email with patients could create added work for already busy clinic staff. Participants were evenly split over whether email would or would not protect the privacy of health information (Fig. 3).

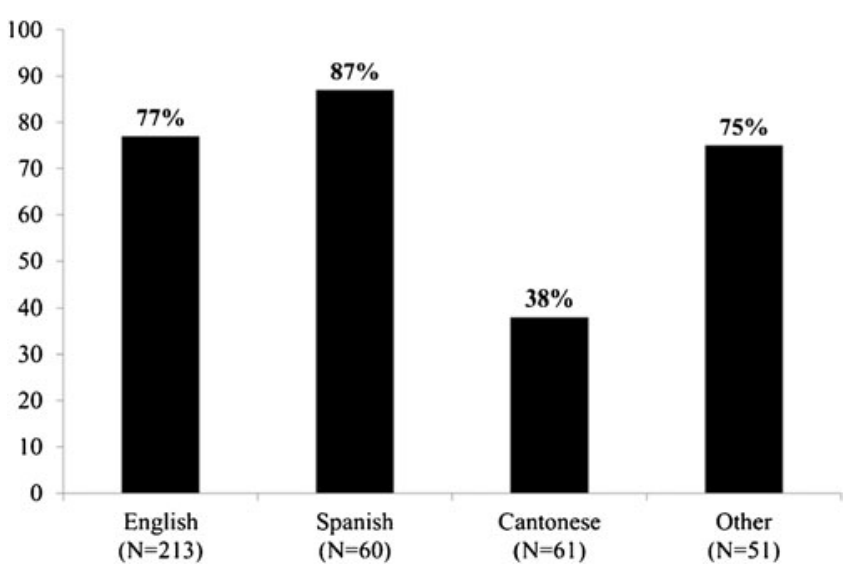

Figure 2. Participants interested in email to communicate with health provider, by language. 
Table 2. Proportion Reporting Interest in Electronic Communication with Provider by Patient Demographics

\begin{tabular}{|c|c|c|c|c|}
\hline N (Row \%) & $\begin{array}{l}\text { Number } \\
\text { of } \\
\text { Participants } \\
\text { Overall, } \\
N=408 \\
\text { (percentage) }\end{array}$ & P-value & $\begin{array}{l}\begin{array}{l}\text { Number } \\
\text { of E-mail } \\
\text { Users Only, } \\
N=241 \\
\text { (percentage) }\end{array}\end{array}$ & P-value \\
\hline Age & & $<0.01$ & & 0.61 \\
\hline$\leq 40$ & $110(87)$ & & $100(93)$ & \\
\hline$\overline{4} 1-60$ & $132(76)$ & & $96(92)$ & \\
\hline $60+$ & 37 (41) & & $19(86)$ & \\
\hline Gender & & & & 0.08 \\
\hline Female & 157 (69) & 0.50 & $125(89)$ & \\
\hline Male & $121(74)$ & & 90 (97) & \\
\hline Income & & 0.05 & & 0.12 \\
\hline $\begin{array}{l}<20 \mathrm{~K} \\
20 \mathrm{~K}+\end{array}$ & $\begin{array}{r}166(69) \\
88(79)\end{array}$ & & $\begin{array}{r}126(91) \\
78(96)\end{array}$ & \\
\hline Education & & $<0.01$ & & 0.78 \\
\hline $\begin{array}{l}<\text { High } \\
\text { school }\end{array}$ & $38(57)$ & & $18(90)$ & \\
\hline $\begin{array}{l}\text { High school/ } \\
\text { GED }\end{array}$ & $67(62)$ & & $48(94)$ & \\
\hline College & $117(82)$ & & $102(93)$ & \\
\hline $\begin{array}{c}\text { Graduate } \\
\text { school }\end{array}$ & $32(80)$ & & $31(89)$ & \\
\hline Housing & & 0.45 & & 0.18 \\
\hline Own & $20(67)$ & & $16(100)$ & \\
\hline Rent & $231(73)$ & & $190(92)$ & \\
\hline Homeless & $22(65)$ & & $9(80)$ & \\
\hline Race & & $<0.01$ & & 0.35 \\
\hline White & $63(85)$ & & $61(94)$ & \\
\hline Black & $65(72)$ & & $45(88)$ & \\
\hline Asian/PI & $51(51)$ & & $40(89)$ & \\
\hline $\begin{array}{c}\text { Hispanic/ } \\
\text { Latino }\end{array}$ & $68(86)$ & & $45(98)$ & \\
\hline Other & $14(70)$ & & $10(100)$ & \\
\hline Language & & $<0.01$ & & 0.34 \\
\hline English & 164 (77) & & $132(93)$ & \\
\hline Spanish & $52(87)$ & & $33(97)$ & \\
\hline Cantonese & $23(38)$ & & $19(90)$ & \\
\hline Other & $38(75)$ & & $30(86)$ & \\
\hline English & & $<0.01$ & & 0.51 \\
\hline Proficiency & & & & \\
\hline Very good & 187 (79) & & 153 (94) & \\
\hline Good & $37(76)$ & & $25(86)$ & \\
\hline Not good & $41(66)$ & & $30(91)$ & \\
\hline Not at all & $12(32)$ & & $6(100)$ & \\
\hline
\end{tabular}

\section{DISCUSSION}

In our study of ethnically diverse, low-income patients, we found that the majority use email; nearly three out of every four patients were interested in using email for health communication with their medical providers. While the clear majority of study subjects expressed interest in email use with health care providers, less than $20 \%$ had used email to communicate with providers. This demonstrates an unmet interest in health-related electronic communication among patients in the safety net, especially in younger populations where use of internet-based communication is common. Our findings are consistent with national surveys showing the digital divide in internet use is shrinking faster than might have been expected. ${ }^{23}$ Our findings in this safety net setting demonstrate an interest in electronic communication with providers that is at least as great as other studies among Medicaid and general U.S. population samples ${ }^{24,25}$ - suggesting that vulnerable populations are not lagging behind in their desire for new modes of healthcare access and communication.

Similar to previous work, our study found disparities in email use and interest according to educational attainment, age, race/ethnicity, and language. A strong predictor of interest in email communication for health matters was current use of an email account. Yet even among those without email access, a significant minority were interested in emailing with their providers. With respect to racial and ethnic disparities in email use, white participants reported greater use of email than other groups and Asian participants were least likely to email regularly. Email use was not highest among Latinos, but interest in email use for health related communication was highest among Spanishspeaking groups. This difference remained even after adjustment for the relatively younger average age of the Spanish-speaking participants.

Patients were largely in favor of using email technology for health, and agreed it would likely improve overall clinical communication and clinic efficiency. Many patients in our study also thought that this technology would create more work for clinic staff and would not replace face-toface visits. Interestingly, participants were quite aware of the busy practices of their clinicians and were sensitive to this in their thinking about electronic communication with their providers. This suggests that patient perceptions of a busy practice may influence how much they choose to communicate with their providers electronically. As in prior studies, ${ }^{26}$ some patients felt that email may not protect their privacy or the confidentiality of their health information. Design of electronic patient health portals and communication tools should be sensitive to concerns over privacy in vulnerable populations. Our finding that nearly all patients using text messages were interested in receiving text messages regarding their health care raises a number of logistical and policy issues, particularly for safety net systems where many patients have cell phones but not computers. A number of recent health interventions using text messaging ${ }^{27,28}$ have shown promise addressing selfmanagement behaviors. However, privacy concerns remain because of lack of encryption and cell phone sharing. ${ }^{29}$ Medical text messages and access to electronic health portals in public settings such as the public library should both be considered in the creation of privacy safeguards for electronic health communication tools.

Limitations of this study include its sampling from a single urban geographic area, though we surveyed patients at six sites and in three languages to yield a diverse study population. Moreover, the majority of the literature in this area has been generated in well-resourced settings, and our study was designed to address this gap. Despite presenting the study to participants as "a survey about email use", our low rate of participant refusal to enroll 


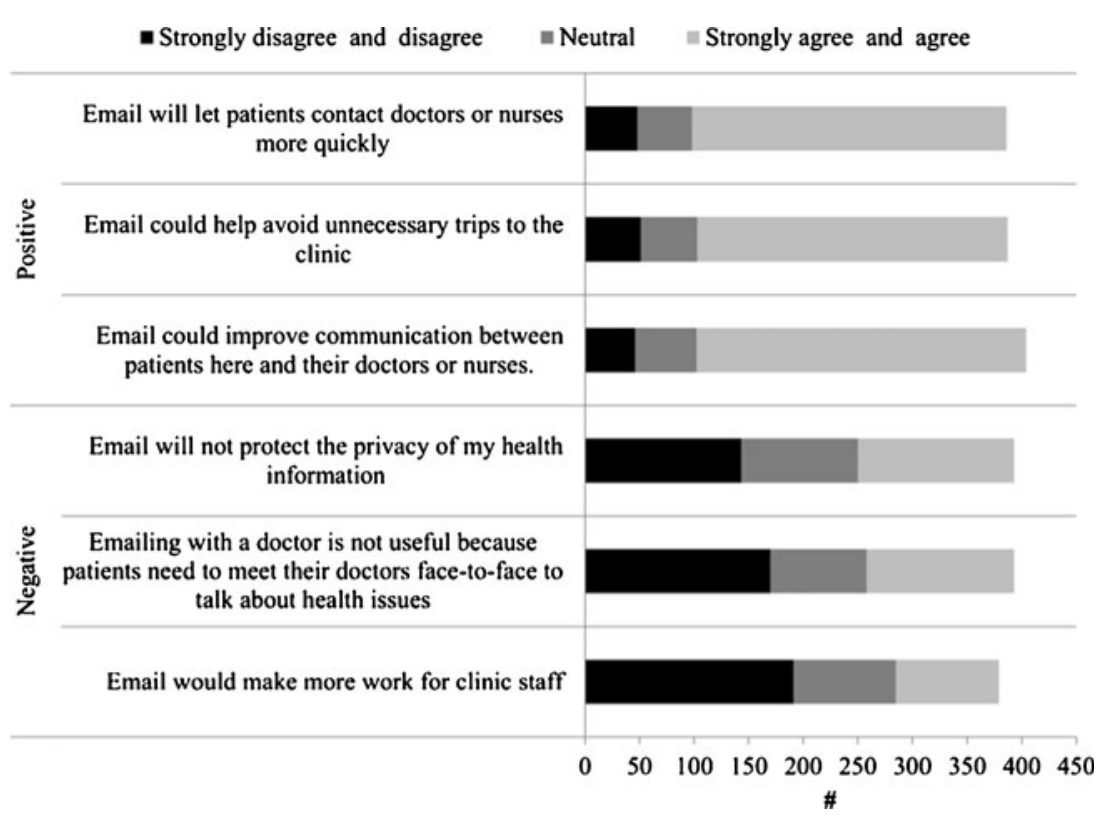

Figure 3. Statements about email use.

makes it unlikely that our findings reflect a systematic bias toward participation among those already using email. Our sample from FQHCs may not generalize to all safety net clinics and participants from a waiting room may not be representative of all patients empaneled to a clinic. We did not measure frequency of clinic use and could not control for patients who visit infrequently and may be less likely to email providers. Though some measurement items were similar to the Pew Research Center's validated Internet and American Life Project survey ${ }^{23}$ and our questionnaire was vetted by content experts and clinicians practicing in the survey setting, our survey tool had not been previously validated. As with all questionnaire studies in a clinical setting, our study design creates the potential for social desirability bias in responses, though study staff were trained to remain neutral with respect to survey responses and were culturally congruent. We did not assess betweengroup variability in Likert scale responses specifically due to cultural differences. We did not directly ask about home internet access, though we did ask participants where they used email and most reported use at home, which implies internet access there.

Based on our findings, access to electronic communication tools (internet, email, and text messaging) is unlikely to be the primary barrier to adoption of web-based healthrelated communication in the medical safety net. To avoid creating new disparities in the use of and benefit from technology for health-related communication, resource-poor health systems should invest in technologies that allow for robust communication between clinicians and patients, training for patients who may not be facile with technology, and ways to tailor electronic health communication to patient language and literacy level ${ }^{30,31}$. Usability testing of these technologies in vulnerable populations will be critical to ensure all patients benefit equally. Patientfacing communication technologies are urgently needed in under-resourced settings where they may reduce strain on provider capacity, increase efficiency, and potentially improve quality.

\section{Acknowledgements:}

Contributors: We thank Dr. Alicia Fernandez for her comments on the survey tool, as well as Drs. Mark Ghaly, Hali Hammer, Shannon Thyne, Lisa Golden, Albert Yu, Alice Chen, and Catherine James for their clinics' participation in the study.

Funders: Adam Schickedanz was supported by The University of California San Francisco Clinical and Translational Science Institute. Urmimala Sarkar was supported by AHRQ KO8 HSO17594. The funding sources had no role in the study design, data collection, data analysis, manuscript preparation, or decision to submit for publication.

Prior Presentations: Earlier results were presented at the Society of General Internal Medicine's annual conference in May of 2012 and the AcademyHealth annual research meeting in June of 2012.

Conflict of Interest: The authors declare that they do not have a conflict of interest.

Corresponding Author: Adam Schickedanz, MD; Department of Pediatrics, University of California San Francisco, 505 Parnassus Avenue, M691, San Francisco, CA 94143, USA (e-mail: Adam.schickedanz@ucsf.edu).

\section{REFERENCES}

1. Fox S. The Social Life of Health Information, 2011. Washington, DC: Pew Research Center; 2011. 
2. Liederman EM, Lee JC, Baquero VH. The impact of patient-physician web messaging on provider productivity. Management. 2005;19(2):8186.

3. Delbanco T, Sands DZ. Electrons in flight-e-mail between doctors and patients. The New Engl J Med. 2004;350(17):1705-7. Available at: http://www.ncbi.nlm.nih.gov/pubmed/15102994, accessed July, 2012.

4. Ralston JD, Rutter CM, Carrell D, et al. Patient use of secure electronic messaging within a shared medical record: a cross-sectional study. J Gen Intern Med. 2009;24(3):349-55. Available at: http://www.pubmedcentral. nih.gov/articlerender.fcgi?artid=2642567\&tool=pmcentrez\&rendertype= abstract, accessed July 2012.

5. Zhou YY, Kanter MH, Wang JJ, Garrido T. Improved quality at Kaiser Permanente through e-mail between physicians and patients. Health Affairs (Project Hope). 2010;29(7):1370-5. Available at: http:// www.ncbi.nlm.nih.gov/pubmed/20606190, accessed July, 2012.

6. Rosen P, Kwoh CK. Patient-physician e-mail: an opportunity to transform pediatric health care delivery. Pediatrics. 2007;120(4):701-6. Available at: http://www.ncbi.nlm.nih.gov/pubmed/17908755, accessed July 2012.

7. Ralston JD, Hirsch IB, Hoath J, Mullen M, Cheadle A. Web-based collaborative care for type 2 diabetes. Diabetes Care. 2009;32(2):234-239.

8. Harris LT, Haneuse SJ, Martin DP. Diabetes quality of care and outpatient utilization with electronic patient-provider messaging. Diabetes Care. 2009;32(7):1-5.

9. Anon. Department of Health and Human Health Information Technology: initial set of standards, implementation specifications, and certification criteria for electronic health record technology; Federal Register. 2010:166.

10. Anon. Health Information Technology for Economic and Clinical Health (HITECH) Act, Title XIII of Division A and Title IV of Division B of the American Recovery and Reinvestment Act (ARRA). 2009.

11. Lenhart A, Rainie L, Fox S, et al. Who's Not Online. Washington DC: Pew Research Center; 2000.

12. Roblin DW, Houston TK, Allison JJ, Joski PJ, Becker ER. Disparities in use of a personal health record in a managed care organization. Journal of the American Medical Informatics Association: JAMIA. 2009;16(5):683-9. Available at: http://www.pubmedcentral.nih.gov/ articlerender.fcgi ?artid $=2744719 \&$ tool=pmcentre $\&$ rendertype $=$ abstract, accessed July 2012.

13. Ancker JS, Barrón Y, Rockoff ML, et al. Use of an electronic patient portal among disadvantaged populations. J Gen Intern Med. 2011;26 (10):1117-23. Available at: http://www.ncbi.nlm.nih.gov/pubmed/ 21647748 , accessed July 2012.

14. Yamin CK, Emani S, Williams DH, et al. The digital divide in adoption and use of a personal health record. Arch Intern Med. 2011;171(6):56874. Available at: http://www.ncbi.nlm.nih.gov/pubmed/21444848, accessed July 2012.

15. Sarkar U, Karter AJ, Liu JY, et al. Social disparities in internet patient portal use in diabetes: evidence that the digital divide extends beyond access. J Am Med Inf Assoc: JAMIA. 2011;18(3):318-21. Available at: http://www.pubmedcentral.nih.gov/articlerender.fcgi?artid=3078675\& tool=pmcentrez\&rendertype=abstract, accessed July 2012.

16. Carroll AE, Rivara FP, Ebel B, Zimmerman FJ, Christakis DA. Household computer and Internet access: the digital divide in a pediatric clinic population The Regenstrief Institute for Health Care , Indianapolis , IN. Symposium A Q J Mod Foreign Lit. 2005:111-115.
17. Sarkar U, Karter AJ, Liu JY, et al. The literacy divide: health literacy and the use of an internet-based patient portal in an integrated health system-results from the diabetes study of northern California (DISTANCE). J Health Commun. 2010;15 Suppl 2(922973516):183-96. Available at: http://www.pubmedcentral.nih.gov/articlerender.fcgi? artid $=3014858 \&$ tool=pmcentrez\&rendertype=abstract, accessed July 2012.

18. Goel MS, Brown TL, Williams A, et al. Disparities in enrollment and use of an electronic patient portal. J Gen Intern Med. 2011;26(10):1112-6. Available at: http://www.ncbi.nlm.nih.gov/pubmed/21538166, accessed July 2012.

19. Lyles C, Harris L, Jordan L, et al. Patient race/ethnicity and shared medical record use among diabetes patients. Medical Care. 2012;50 (5):434-440.

20. Jha AK, DesRoches CM, Shields AE, et al. Evidence of an emerging digital divide among hospitals that care for the poor. Health Affairs (Project Hope). 2009;28(6):w1160-70. Available at: http:// www.ncbi.nlm.nih.gov/pubmed/19858142, accessed July 2012.

21. Chang BL, Bakken S, Brown SS, et al. Bridging the digital divide: reaching vulnerable populations. J Am Med Inform Assoc. 2004;11 (6):448. Available at: http://jamia.bmj.com/content/11/6/448.short, accessed July 2012.

22. Hsu J, Huang $\mathbf{J}$, Kinsman $\mathbf{J}$, et al. Use of e-Health services between 1999 and 2002: a growing digital divide. J Am Med Inform Assoc. 2005;12(2):164. Available at: http://171.67.114.118/content/12/2/ 164.abstract, accessed July 2012.

23. Zickuhr K, Smith A. Digital Differences. Washington, DC: Pew Internet and American Life Project; 2012.

24. Lobach DF, Willis JM, Macri JM, Simo J, Anstrom KJ. Perceptions of Medicaid beneficiaries regarding the usefulness of accessing personal health information and services through a patient Internet portal. AMIA Annual Symposium Proceedings 2006:509-13

25. Optum Institute. Meaningful Consumer Engagement: A Survey of Stakeholder Views. http://institute.optum.com/technologies/ / media/OptumInstitute/Page_Elements/Articles/Institute_HealthIT_ FINAL.pdf, accessed July 2012.

26. Andrea H, James W, David K, Kim R, David Y, Steven P, Deborah D, Kuck Sarah OE. Patient experiences and attitudes about access to a patient electronic health care record and linked web messaging. J Am Med Inform Assoc. 2004;11(6):505-514.

27. Guinn CC, Clough SS, Minor JM, Lender D, Okafor MC, GruberBaldini A. WellDoc mobile diabetes management randomized controlled trial: change in clinical and behavioral outcomes and patient and physician satisfaction. Diabetes Technol Ther. 2008;10(3):160-168.

28. Fischer HH, Moore SL, Ginosar D, Davidson AJ, Rice-Peterson CM, Durfee MJ, et al. Care by cell phone: text messaging for chronic disease management. Am J Manag Care. 2012;18(2):e42-e47.

29. Prestigiacomo J. Secure messaging via the cloud and mobile devices: data security issues emerge with new technologies. Health Inf. 2011;28 (5):24-29.

30. Gibbons M, Casale C. Reducing disparities in health care quality: the role of health IT in underresourced settings. Med Care Res Rev. 2010;67 (5): 155S-162S.

31. Gibbons M, Fleisher L, Slamon R, et al. Exploring the potential of Web 2.0 to address health disparities. J Heal Commun. 2011;16:7789 . 